\title{
Kesantunan Berbahasa pada Anak Melalui Pembiasaan
}

\author{
Juhaeni ${ }^{1}$, Wahyuningtias Ludiawati ${ }^{2}$, Safaruddin ${ }^{3}$, Lisfiana Nur Laili ${ }^{4}$, Lutfiatus Zahrotul \\ Ulfa $^{5}$, Putri Ambarwati ${ }^{6}$ \\ 1, 2,4,5,6 Universitas Islam Negeri Sunan Ampel Surabaya, Indonesia \\ ${ }^{3}$ IAIM Sinjai, Indonesia
}

\section{DOI : https://doi.org/10.15642/jeced.v2i2.942}

\begin{abstract}
The habit of politeness in language in children aged 5-6 years is something that is crucial. This study aims to analyze the impact of using the word do not replace the word sorry for children. This study uses qualitative methods with data triangulation techniques. Samples taken were students of group A PGRA Mamba'ul Hisan Surabaya. Data collection techniques used are 1) Making observations in class A1, A2, A3, 2) Interview with class teachers, 3) Analyzing data based on theory, 4) Summing up the results obtained. The data taken consisted of 3 samples from 3 groups who were accustomed to politeness in language. The results obtained include: children can accept mistakes, children can be more polite and more polite in talking, children are accustomed to gentle reprimands.
\end{abstract}

\section{Article Info}

Article history:

Received: December 12, 2020

Approved: December 30, 2020

Published online: December 31, 2020

Keywords:

habituation,

politeness in language,

apology,

said no.

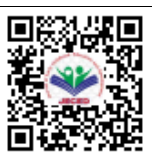

\begin{abstract}
Abstrak
Pembiasaan Kesantunan berbahasa pada anak usia 5-6 tahun merupakan sesuatu yang krusial. Penelitian ini bertujuan untuk menganalisis dampak penggunaan mengganti kata jangan dengan kata maaf terhadap kesantunan berbahasa anak. Penelitian ini menggunakan metode daskriptif kualitatif dengan teknik pengumpulan data melalui observasi, wawancara dan dkumentasi. Sampel yang diambil merupakan siswa kelompok A PGRA Mamba'ul Hisan Surabaya. Teknik pengambilan data yang digunakan adalah 1) Melakukan observasi di kelas A1, A2, A3, 2) Wawancara dengan guru kelas, 3) Menganalisis data berdasarkan teori, 4) Menyimpulkan hasil yang diperoleh. Data yang diambil 3 kelompok yang membiasakan kesantunan berbahasa. Hasil yang diperoleh antara lain: anak dapat menerima kesalahan, anak dapat lebih santun dan lebih sopan dalam berbicara, anak terbiasa dengan teguran yang lembut.
\end{abstract}

\begin{tabular}{l} 
Informasi Artikel \\
\hline Riwayat Artikel \\
Diterima: 12122020 \\
Disetujui: 30122020 \\
Publikasi online: 31122020 \\
\hline Kata kunci: \\
Pembiasaan, \\
Kesantunan berbahasa, \\
kata maaf, \\
kata jangan \\
\\
cc) (i) (2)
\end{tabular}




\section{PENDAHULUAN}

Anak usia 0 sampai 7 tahun termasuk anak usia dini. Pada masa tersebut anak berada pada fase golden age atau masa keemasan (Pusparini et al., 2019). Dalam masa ini rasa peka anak mulai tumbuh dan berkembang begitu cepat . Rasa ingin tahu anak yang sangat besar adalah salah satu karekteristik anak yang sangat menonjol, karena itu pendidik harus memberikan stimulasi yang tepat bagi anak (Taseman et al., 2020; Alfin \& Pangastuti, 2020). Salah satunya mengganti kata jangan dengan kata maaf. Hal ini berkaitan dengan rasa ingin tahunya yang besar termasuk penggunaan kata jangan bagi anak. Penggunaan kata jangan justru dapat memberikan respon kebalikan yang menjadikan anak penasaran akan hal yang dilarang. Terlalu sering menggunakan kata jangan menyebabkan mengganggu kesenangan anak, perkataan itu memang akan menghentikan tindakan anak namun memungkinkan anak mengulang tindakan tersebut. Misalnya seperti ketika anak berlari-larian di kelas, guru dapat menganti kata "jangan berlari-lari" dengan menggunakan kata "mohon maaf, ayo kita duduk". Penggunaan kata jangan juga dapat menimbulkan rasa kesal, jengkel, dan marah.

Untuk mengungkapkan diri, biasanya orang-orang tidak hanya menghasilkan ujaran yang mengandung kata dan struktur gramatikal akan tetapi, memperlihatkan tindakan melalui tuturan mereka. Sebanding dengan kebiasaan menghargai orang lain, terdapat kata maaf, kalimat yang realistis, serta keadaan yang membutuhkan ketegasan, fakta, sindiran tetapi halus, pujian yang tulus, dapat menyampaikan pendapatnya, lalu sesuai dengan situasi dan tempat, lalu memakai kata-kata yang halus atau tidak menyinggung orang lain (Dari et al., 2017).

Guru dalam tradisi Jawa biasanya disebut dengan "digugu lan ditiru" (orang yang dipercaya dan diikuti) oleh karena itu guru harus memperhatikan pengelolaan kesantunan bahasa. Penggantian kata jangan dengan kata maaf perlu adanya pembiasaan. Sama halnya dengan PGRA Mambaul Hisan Wiyung Surabaya yang menerapkan pembiasaan mengganti kata jangan dengan maaf. Pembiasaan menurut (H.E.Mulyasa, 2017), merupakan cara yang sudah lama dilakukan, ia menafsirkan pembiasaan yaitu kegiatan yang dengan sadar dilakukan secara terus-menerus agar menjadi pembiasaan. Misalnya ketika anak sedang bergurau saat jam pelajaran, guru mengingatkan dengan kata "mohon maaf, ustadzah menjelaskan terlebih dahulu ya?". Penerapan kata maaf di RA Mambaul Hisan telah menjadi kebiasaan, terutama di kelompok A. Ketika guru mengucapkan kata maaf seringkali menggunakan intonasi yang santun dan lembut serta tidak lupa dengan tersenyum. Penggunaan kata maaf tersebut memberikan dampak yang positif terhadap anak, anak tidak merasa malu atau marah ketika diingatkan oleh guru, justru anak dapat menerima perkataan guru dengan baik.

Dari hasil telaah, terdapat hasil penelitian yang telah ada sebelumnya. Telah ditemukan beberapa hasil yang memiliki hasil yang relevansi terhadap yang akan dilakukan. Penelitian disebut diantaranya adalah, penelitian oleh (Hamidah, 2019) mengenai cara mendidik anak usia dini terhadap kesantunan berbahasa. Hasil dari penelitian ini bahwa terdapat perbedaan pola asuh antara sekolah islam dan sekolah umum. Kesantunan bahasa anak akan berpengaruh terhadap pembiasaan cara mendidik anak dalam kehidupan sehari-hari. Terdapat berbagai strategi yang dapat dilakukan untuk pembentukan karakter dalam kesantunan berbahasa. Pembiasaan kata maaf dan tolong, dan merendahkan intonasi suara, mengandung nilai positif, memberikan stimulus pada anak, serta menurut pedoman Al-Qur'an yang dapat diajarkan terhadap anak.

Penelitian lain yang serupa adalah oleh (Candrasari \& Badi'ah, 2014) penelitian menggunakan desain survei analitik. Responden penelitian adalah orang tua anak yang berusia 36 tahun di RA Semai Benih Bangsa Al-Fikri Manca Bantul Yogyakarta.

Pembiasaan dalam mengganti kata jangan dengan maaf sangat jarang ditemui. Maka berdasarkan latar belakang tersebut peneliti mengkaji lebih lanjut dengan judul "Pembiasaan Mengganti Kata Jangan dengan Kata Maaf Terhadap Kesantunan Bahasa Anak Kelompok A di RA Mamba'ul Hisan Surabaya”. 


\section{METODE}

Penelitian ini menggunakan metode deskriptif kualitatif, dengan sasaran yang diteliti yaitu anak kelompok A. Teknik pengumpulan data dalam penelitian ini menggunakan teknik wawancara, observasi dan dokumentasi (Rahmawati et al., 2019). Penelitian ini dilaksanakan pada bulan Agustus hingga September 2019. Data penelitian ini didapatkan dengan cara mengikuti kegiatan sasaran atau informan, merekam dengan menggunakan kamera handphone, lalu menstranskipsikan berupa tulisan kegiatan sasaran menjadi sebuah tulisan, sehingga dapat dianalisa dan ditindak lanjuti.

Taknik wawancara ini dilaksanakan terhadap sasaran pendukung dalam penelitian ini wali kelas kelompok A. Sumber objek penelitian tidak mengetahui bahwa ia sedang diteliti. Peneliti melakukan pemantauan dan terlibat dalam proses belajar-mengajar di kelas.

Teknik penelitian ini menggunakan triangulasi data, peneliti membandingkan hasil wawancara dengan observasi untuk mengecek kebenaran informasi yang didapatkan. Setelah data didapatkan, ada beberapa tahapan yang dilakukan analisis untuk mendapatkan data yaitu menggunakan tahapan observasi, wawancara, dan kajian.

\section{PEMBAHASAN}

Kesantunan adalah suatu tindakan yang disepakati bersama oleh suatu kelompok masyarakat tertentu agar kesantunan menjadi syarat terpenting dan disepakati oleh perilaku sosial (Apriliani, 2019). Maka dari itu kesantunan diartikan tata krama dan sudah menjadi sebuah tradisi masyarakat (Asista, 2019). Kesantunan bersifat mudah dan dapat dilakukan oleh masyarakat. Perkataan dapat disebut santun dalam suatu kelompok masyarakat tertentu, jadi perkataan santun satu kelompok masyarakat dengan kelompok masyarakat lain memiliki tingkat kesantunan yang berbeda. Kesantunan (politeness) adalah tingkah laku yang diwujudkan dengan melalui cara yang benar dan beretika (Zamzani et al., 2012). Kesantunan ialah fenomana pencampuran budaya, tolak ukur berbahasa berbeda disetiap kelompok masyarakat. Kesantunan memiliki tujuan yaitu membuat suasana interaksi dengan orang lain menjadi menyenangkan dan efisien. Penelitian kesantunan menelaah tentang penggunaan bahasa (languange use) dalam masyarakat tertentu yang memiliki latar belakang, situasi sosial dan budaya yang berbeda (Pamungkas, 2016).

Menurut Chaer kesantunan memiliki ciri-ciri diantara lain, tidak memaksa apa kehendak penutur, perkataan memberikan altenatif tindakan kepada lawan tutur, lawan tutur merasa senang atas apa yang penutur bicarakan. Kesantunan bahasa terlihat dari cara berbicara kepada lawan tutur. Berkomunikasi perlu mengacu pada norma dan nilai budaya setempat (Dari et al., 2017).

Tata cara berbahasa harus sesuai dengan unsur-unsur budaya yang terdapat pada masyarakat. Apabila seseorang memiliki tatacara berbahasa yang tidak sesuai dengan norma budaya maka ia akan mendapatkan nilai negatif, misal di tuduh orang yang sombong, angkuh, tak acuh, egois. Kesantunan bahasa bisa dilakukan pembicara mematuhi prinsip kesantunan berbahasa yang berlaku di masyarakat. Sehingga pembicara harus bertutur sesuai dengan budaya. Hal tersebut berfungsi untuk menjaga hubungan baik dengan lawan bicara.

Kesantunan berbahasa pada dasarnya kesantunan memiliki 6 prinsip yaitu menerapkan prinsip yang menghindari pemakaian kata tabu (taboo), pemakaian ungkapan uefemisme yakni sebuah pengungkapan halus serta penggunaaan kata honorifik. Dalam interaksinya pembicara membutuhkan dasar kesantunan (piliteness principle). Prinsip kesantunan memiliki beberapa maxim yaitu (Siti Norhidayah, 2015):

1. Maksim Kebijaksanaan (Tact Maxim)

Maksim kebijaksaan adalah dasar kesantunan dimana pembicara harusnya berlandaskan pada prinsip untuk selalu mengecilkan ego dalam dirinya sendiri dan memaksimalkan keuntungan berada di lawan tutur saat berinteraksi. Pembicara yang berlandaskan pada maksim kebijaksanaan dapat di kategorikan sebagai orang santun. Apabila dalam bertutur orang berpegang teguh pada maksim kebijaksanaan maka akan terhindar dari sikap dengki, iri hati dan sikap-sikap lain yang kurang santun kepada lawan bicara (Wahidah \& Wijaya, 2017).

2. Maksim Kedermawanan (Generocity Maxim) 
Maksim ini disebut juga dengan maksim kemurahan hati. Para pembicara dapat diharapkan menghormati lawan bicara. Penghormatan pembicara terjadi apabila pembicara dapat mengurangi keuntungan bagi diri sendiri dan memaksimalkan keuntungan lawan bicara.

3. Maksim Penghargaan (Approbation Maxim)

Dalam maksim ini, orang dianggap santun apabila dalam bertutur selalu berusaha memberikan penghargaan. Dengan maksim ini diharapkan agar pembicara dan lawan bicara tidak saling mengejek, mencaci, dan menjatuhkan orang lain. Menerapkan maksim penghargaan dapat meminimalkan hinaan orang lain dan mengoptimalkan memberi penghargaan kepada orang lain (Rohali., 2011).

4. Maksim Kesederhanaan (Modesty Maxim)

Maksim ini disebut juga dengan maksim rendah hati, dimana pembicara diharuskan dapat bersikap rendah hati dengan cara meminimalkan pujian terhadap diri sendiri. Maksim kesederhanaan meminimalkan penghargaan pada diri sendiri dan mengoptimalkan penghargaan kepada orang lain. Dalam maksim ini melatih seseorang sikap dan bicara dengan sederhana tidak menonjolkan sikap sombong.

5. Maksim Permufakatan (Agreement Maxim)

Maksim permufakatan biasa disebut dengan maksim kecocokan. Maksim ini menekankan penutur saling membina kecocokan dalam kegiatan interaksi terdapat kemufakatan antara pembicara dan lawan bicara dalam tindakan pembicaraan maka mereka sudah dapat dikatakan santun.

6. Maksim Kesimpatisan (Sympath Maxim)

Dalam maksim ini pembicara diharapkan memaksimalkan sikap simpati anatar pihak pembicara dan lawan bicara. Sikap antipati terhadap pembicara akan dianggap sebagai sikap tidak santun. Sikap simpati kepada orang lain bisa dilihat dari senyuman, anggukan, gandengan tangan, dan sebagainya (Dasar, 2014).

Guru dapat menerapkan bahasa yang positif pada anak dengan cara yang efektif seperti (Pamungkas, 2016):

1. Memberikan contoh kata yang positif pada anak.

2. Ketika berbicara, kata yang diucapkan harus secara perlahan serta jelas sehingga mudah dipahami oleh anak.

3. Guru dapat membenarkan kesalahan kata yang diucapkan oleh anak.

Di PGRA Mamba'ul Hisan memiliki strategi untuk membiasakan bersikap santun, yaitu membiasakan karakter positif di awal tahun ajaran baru selama 2 bulan. Mereka menunda kegiatan pembelajaran efektif tema dan menggantinya dengan pembiasaan baik terutama untuk siswa-siswi yang baru masuk. Pembiasaan tersebut adalah mengucapkan salam, berjabat tangan, sayang terhadap teman, mandiri, memanggil temannya dengan sebutan mas atau mbak, dan pembiasaan karakter positif lainnya.

Kesantunan berbahasa mempunyai strategi yang mungkin dapat dilakukan, yaitu (Hamidah, 2019):

1. Mengubah kalimat perintah dengan kalimat tanya.

2. Melatih anak untuk sering mengucapkan kata "tolong" pada saat memerlukan bantuan dan mengucapkan kata "maaf" bila telah berbuat kesalahan sekecil apapun.

3. Menurunkan intonasi suara, tetapi masih memberi tekanan intonasi pada kata tertentu untuk memperjelas maksud dari kata tertentu.

4. Memberikan motivasi terhadap anak untuk menumbuhkan rasa percaya diri seorang anak.

5. Selalu memberi reward yang positif. Berbentuk pujian maupun sanjungan ketika anak mampu melakukan sesuatu yang baik.

6. Tidak menuntut apapun, tetapi berikan kesempatan yang luas untuk anak belajar dan mengeksplor diri.

7. Memberikan suri tauladan yang baik dalam berbahasa kepada yang lebih muda maupun yang lebih tua.

8. Mengikuti aturan Allah yang sudah tertera dalam Al- Qur'an. Sehingga anak dapat berkata dengan baik. 
Menurut Leech bahwasannya menyatakan bahwa kesantunan memiliki 8 karakteristik yakni (Yenni et al., 2018) :

1. Sikap kesantunan adalah sikap yang harus dilakukan, ada saat kita boleh berlaku tidak sopan namun tetap dengan alasan yang jelas.

2. Sikap santun dan tidak santun memiliki tingkatan dan variasi yang berbeda.

3. Sesuatu hal yang dianggap normal bisa disebut santun pada situasi tertentu.

4. Kesantunan dapat berlaku kapanpun pada situasi tertentu.

5. Terdapat asimetris resiprokal antar dua kelompok.

6. Kesantunan memiliki aspek yang dapat diwujudkan dengan perilaku yang memiliki tingkatan kesantunan.

7. Kesantunan adalah interaksi nilai antara penutur dengan kelompok lain.

8. Kesantunan biasanya mempertahankan keseimbangan nilai antar penutur dan lawan penutur.

Dengan membiasakan mengganti kata jangan dengan kata maaf pada awal-awal ajaran baru. Maka secara tidak langsung akan menimbulkan kebiasaan pada anak dan akan terbentuk dengan sendirinya. Karena di PGRA Mamba'ul Hisan membiasakan tidak ada kekerasan pada Ustadzah dan anak-anak. serta kebiasaan tersebut akan berpengaruh pada kehidupan sehari-hari anak.

Pembiasaan kata jangan dengan kata maaf lebih baik dibiasakan setiap hari pada anak. hal ini bertujuan untuk memunculkan kebiasaan-kebiasaan positif pada anak. Kondisi ini sering di jumpai di PGRA Mamba'ul Hisan, guru sering mengucapkan kata-kata positif seperti :

1. Pada hari Jum'at, 23 Agustus 2019. Pukul 08.34 WIB

Hari ini anak-anak pergi berenang bersama Ustadzah, karena air di kamar mandi tidak bisa menyala maka Ustadzah mengatakan bahwa hari ini anak-anak tidak bisa mandi selepas renang.

Guru : Mohon maaf, hari ini Ustadzah tidak bisa memandikan anak-anak memakai sampo dan sabun karena airnya mati.

2. Pada hari Rabu, 11 September 2019. Pukul 08.18 WIB

Hari ini Ustadzah akan menyiapkan meja untuk kegiatan sentra, namun ada salah satu siswa berada di atas meja. Dengan nada santun dan lembut Ustadzah menegur siswa tersebut.

Guru : Mohon maaf, permisi Ustadzah mau menata meja bisakah anaknya turun?

3. Pada hari Kamis, 19 September 2019. Pukul 08.25 WIB

Hari ini anak-anak akan melakukan kegiatan moving sentra, ke sentra agama ada salah satu siswi yang membentuk barisan sendiri.

Guru : Mohon maaf mbak, Kita buat satu barisan saja yuk?

4. Pada hari Senin, 23 September 2019. Pukul 08.11 WIB

Hari ini anak-anak sedang melakukan kegiatan istirahat, lalu ada siswa yang makan sambil berdiri. Ustadzah mengingatkan dengan nada yang santun dan lembut.

Guru : Mohon maaf, ayo kita makan sambil duduk ?

5. Pada hari Selasa, 24 September 2019. Pukul 07.21 WIB

Hari ini anak-anak sedang melakukan kegiatan happy morning sebelum pembelajaran. Lalu ketika Ustadzah mengajak anak-anak menirukan hewan ada salah satu siswa yang tidak tertib ketika menirukan gerakan.

Guru : Mohon maaf, menirukan gerakan hewannya yang sholih yaa?

Peran orang tua juga penting, serta diharapkan orang tua membiasakan sikap-sikap positif yang telah diajarkan di sekolah. Para Ustdzah juga tidak pernah lupa untuk mengingatkan orang tua membiasakan perilaku baik.

Dalam membiasakan mengganti kata jangan dengan kata maaf, anak terbiasa dengan teguran yang lembut, anak lebih santun ketika berbicara baik dengan temannya maupun dengan ustadzah. Ketika di tegur anak tidak akan marah justru anak belajar menerima kesalahan yang diperbuat, ketika anak salah ia tidak merasa seperti direndahkan. Bahkan ustadzah menemukan salah satu anak yang mampu menirukan mengganti kata jangan dengan kata maaf. Anak-anak juga jarang mengucapkan kata jangan. 


\section{SIMPULAN DAN SARAN}

Berbahasa merupakan cara komunikasi verbal yang memiliki aturan dalam hal perilaku, yang ditetapkan dan disepakati oleh masyarakat. Kesantunan memiliki beberapa maksim diantaranya 1) maksim kebijaksanaan, 2) maksim kedermawanan, 3) maksim penghargaan, 4) maksim kesederhanaan, 5) maksim permufakatan, 6) maksim kesimpatisan . Strategi yang dilakukan oleh guru mamba'ul hisan yaitu dengan pembiasaan yang dilakukan secara konsisten, dengan hal itu bisa menanamkan karakter yang baik pada anak. Pembiasaan mengganti kata jangan dengan kata maaf berdampak pada anak diantaranya; 1) anak dapat menerima teguran atau kesalahan yang telah diperbuatnya tanpa bersikap marah, 2) anak juga tidak merasa seperti direndahkan ketika ditegur, 3) anak mulai membiasakan mengucapkan kata maaf pada kehidupan sehari-hari. Berdasarkan kesimpulan di atas peneliti mengajukan beberapa saran sebagai berikut: Pertama, bagi para guru perlu membiasakan kesantunan dalam bahasa, salah satunya membiasakan mengganti kata jangan dengan kata maaf. Kedua, bagi para dosen pendidikan anak usia dini diperlukan banyak contoh hasil penelitian yang beragam mengenai kesantunan berbahasa, terutama pada maksim kesederhanaan.

\section{DAFTAR RUJUKAN}

Alfin, J., \& Pangastuti, R. (2020). Perkembangan Bahasa pada Anak Speechdelay. JECED : Journal of Early Childhood Education and Development, 2(1), 76-86. https://doi.org/10.15642/jeced.v2i1.572

Apriliani, E. I. (2019). Kesantunan Bahasa Anak di PAUD Mekar Sari Gondoriyo Kecamatan Jambul. Indonesian Journal of Early Childhood: Jurnal Dunia Anak Usia Dini, 1(2), 62. https://doi.org/10.35473/ijec.v1i2.358

Asista, A. (2019). Kajian Pragmatik Terhadap Kesantunan Berbahasa Berbasis Kearifan Lokal Dalam HArian Umum Palembang Pos Sebagai Uapaya Penyusunan Bahan Ajar Menganalisis Isi Struktur Teks Negosiasi Bahasa Indonesia Kelas X di SMK. Wistata: Jurnal Pendidikan Bahasa Dan Sastra, 2(2), 142-152.

Candrasari, J. P., \& Badi'ah, A. (2014). Hubungan Pola Asuh Orangtua dengan Perkembangan Bahasa Anak Prasekolah di RA Semai Benih Bangsal Al-Fikri Manca Bantul Yogyakarta. Stikes Aisyiyah Yogyakarta.

Dari, A. W., W, D. E. C., \& Sugiyati, S. (2017). Analisis Kesantunan Berbahasa pada Kegiatan Pembelajaran Kelas VIII E SMPN 2 Kota Bengkulu. 10-21.

Dasar, D. I. S. (2014). Kesantunan Berbahasa dalam Proses Pembelajaran di Sekolah Dasar. 3202.

H.E.Mulyasa. (2017). Menjadi Guru Profesional Menciptakan Pembelajaran Kreatif dan Menyenangkan.

Hamidah, J. (2019). Pola Asuh Orang Tua terhadap Kesantunan Berbahasa Anak Usia Dini (Kajian Pragmatik). 1(1).

Pamungkas, S. (2016). Kesantunan Berbahasa pada Anak-Anak Bilingual di Kabupaten Pacitan Jawa Timur: Kajian Pragmatik (Studi Kasus Kemampuan Anak Mengungkapkan Cerita di Depan Kelas Berdasarkan Teori Kesantunan Asim Gunarwan). Prosiding Prasasti, 298304.

Pusparini, D., Farasyi, R. M., Gupita, N., \& Musayyadah. (2019). Menanammkan Pendidikan Karakter Anak Usia DIni di Masa Golden Age Sesuai Q.S Lukman: 13 - 19. Jurnal Pemikiran, Pendidikan Dan Penelitian Ke-Islaman, 5(1), 19-20.

Rahmawati, A., Juhaeni, J., Aisah, S., Kinasih, A., \& Shibyany, N. (2019). Pengelolaan Kelas Terhadap Siswa Tuna Rungu-Wicara Di Kelompok A1 PGRA Mamba'ul Hisan. JECED : Journal of Early Childhood Education and Development, 1(2), 98-103. https://doi.org/10.15642/jeced.v1i2.463

Rohali. (2011). Kesantunan Berbahasa sebagai Pilar Pendidikan Karakter: Perspektif Sosiopragmatik. Jurnal Pendidikan Karakter, 1(1), 74-97.

Siti Norhidayah. (2015). Kesantunan Berbahasa di Lingkungan Keluarga Masyarakat Banjar di 
Kecamatan Banjar Selatan (Speech Politeness in Banjarese Family in South Banjar District). Jurnal Bahasa, Satra, Dan Pembelajarannya, 5(1), 45-61.

Taseman, T., Safaruddin, S., Erfansyah, N. F., Purwani, W. A., \& Femenia, F. F. (2020). Strategi Guru dalam Menangani Gangguan Keterlambatan Berbicara (Speech Delay) yang Berpengaruh Terhadap Interaksi Sosial Anak Usia Dini di TK Negeri Pembina Surabaya. JECED: Journal of Early Childhood Education and Development, 2(1), 13-26. https://doi.org/10.15642/jeced.v2i1.519

Wahidah, Y. L., \& Wijaya, H. (2017). Analisis Kesantunan Berbahasa Menurut Leech pada Tuturan Berbahasa Arab Guru Pondok Pesantren Ibnul Qoyyim Putra Yogyakarta Tahunajaran 2016/2017 (Kajian Pragmatik). Jurnal Al Bayan: Jurnal Jurusan Pendidikan Bahasa Arab, 9(1). https://doi.org/10.24042/albayan.v9i1.1239

Yenni, E., Yusriati, Y., \& Sari, A. W. (2018). Pola Pengajaran Kesantunan Berbahasa Anak Di Lingkungan Keluarga. Jurnal Tarbiyah, 25(1). https://doi.org/10.30829/tar.v25i1.238

Zamzani, Musfiroh, T., Maslakhah, S., Listiyorini, A., \& Rahayu, Y. E. (2012). Pengembangan Alat Ukur kesantunan Bahasa Indonesia dalam Interaksi Sosial FOrmal Bersemuka. 17(2).

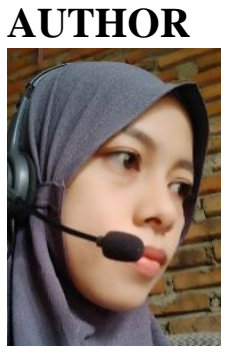

Juhaeni, M.Pd.I, Lahir di Sinjai 31 Mei 1986, ia menempuh pendidikan S-1 IAIM Sinjai pada Jurusan PAI Fakultas Tarbiyah (FT), kemudian pendidikan S2 di Prodi Pendidikan Guru Madrasah Ibtidaiyah (PGMI) Pascasarjana UIN Yogyakarata. Sejak tahun 2016, ia menjadi Dosen Luar Biasa (DLB) Prodi PAI, IAIM Sinjai serta menjadi dosen tetap di UM Surabaya 2007-2018, dan 2018sekarang menjadi dosen tetap UIN Sunan Ampel Surabaya, e-mail: juhaeni@uinsbyac.id

Safaruddin, M.Pd.I, lahir di Sinjai, Sulawesi Selatan, Indonesia pada 31 Mei 1986, menempuh pendidikan dasar hingga sarjana di Kabupaten Sinjai, kemudian melanjutkan pendidikan Magisternya di Universitas Islam Negeri Sunan Kalijaga. Riwayat pekerjaan dimulai pada 2008 hingga 2011 sebagai guru sekolah menengah atas dan Madrasah Ibtidaiyah kemuadian tahun 2013 sebagai dosen di IAIM Sinjai, Sulawesi Selatan dan tahun 2019 menjadi dosen LB UIN Sunan Ampel Surabaya sampai sekarang. e-mail: sarthi339@gmail.com

Wahyuningtias Ludiawati, Lisfiana Nur Laili, Lutfiatus Zahrotul Ulfa, Putri Ambarwati, Merupakan Mahasiswa Aktif Fakultas Tarbiyah UIN Sunan Ampel Surabaya 